\title{
Polynomial Regression Spectra Reconstruction of Arctic Charr's RGB
}

\author{
J. Birgitta Martinkauppi ${ }^{1}$, Yevgeniya Shatilova ${ }^{2}$, Jukka Kekäläinen ${ }^{1}$, \\ and Jussi Parkkinen ${ }^{1}$ \\ ${ }^{1}$ University of Joensuu, PL 111, 80101 Joensuu \\ \{Birgitta.Martinkauppi, Jussi.Parkkinen\} @Cs.joensuu.fi, \\ Jukka.Kekalainen@joensuu.fi \\ ${ }^{2}$ Previously at University of Joensuu \\ evgenikka.joensuu@gmail.com
}

\begin{abstract}
Arctic Charr (Salvelinus alpinus L.) exhibit red ornamentation at abdomen area during the mating season. The redness is caused by carotenoid components and it assumed to be related to the vitality, nutritional status, foraging ability and generally health of the fish. To assess the carotenoid amount, the spectral data is preferred but it is not always possible to measure it. Therefore, an RGB-to-spectra transform is needed. We test here polynomial regression model with different training sets to find good model especially for Arctic charr.
\end{abstract}

Keywords: Arctic Charr (Salvelinus alpinus L.), carotenoid, spectral data, sRGB to spectra transform.

\section{Introduction}

Arctic charr are an endangered fish species living in Finland [1]. It is also grown in fisheries and the individuals are considered valuable assets. The most striking feature of charr is its red abdomen area during the mating season. This red ornamentation is thought to be related to the ability of fish to acquire carotenoids from food since animals cannot synthesize carotenoid components (e.g. [2]). It is assumed to indicate the nutritional status and foraging ability.

Since the carotenoid component seems to be important factor for evaluating vitality, we are developing a system using spectral data for analyzing it. The survival of valuable fish in the quality evaluation is required but up until now, the spectral imaging is too slow, expensive, difficult and cumbersome to use for an ordinary layman. The relation between RGB and spectra has been studied in many papers; see e.g. Baronti et al., Bochko et al., Hardeberg, Heikkinen et al. [3-6]. The $2^{\text {nd }}$ and $3^{\text {rd }}$ order polynomial was chosen for this work.

The applying the transformation for the charr is a challenging task for many reasons. First, since the charr is a natural object, its coloration vary even within one individual. Then its surface and shape also set limitations. Of course, the camera and illumination need to be somehow characterized for the transformation. If the 
system is to be applied in fisheries and test places in nature, the number of test samples are limited.

In this paper, we describe tests with two polynomial regression models and training samples for obtaining the RGB-to-spectral transform dedicated for Arctic charr (see also [7]). The training samples consist of Macbeth chart and few pages from Munsell book. The spectral imaging is applied all the training and fish samples. The transform is calculated for sRGB presentation which is commonly used in many cameras. The sRGB is obtained from spectral data thus making the evaluation camera independent and the results can be thought to be optimal in this sense. To evaluate the quality of the transformation, we employed two commonly used error metrics: Root-MeanSquare error (RMSE) for spectra and $\Delta \mathrm{E}$ of CIELab for human vision.

\section{Spectral Reconstruction Methods for Arctic Charr}

The spectral reconstruction for Arctic charr needs several stages as shown in Fig. 1. First, training set and polynomial are selected and this data is used for calculating the transformation matrix:

$$
\mathrm{X} \cdot \mathrm{W}=\mathrm{Y},
$$

where

$\mathrm{X}=\mathrm{RGB}$ values of camera for the selected samples,

$\mathrm{Y}=$ spectral reflectance corresponding the samples, and

$\mathrm{W}=$ transformation matrix

The transformation matrix is calculated in the least square sense using pseudo-inverse method. The obtained transformation matrix is then applied on the test set which consists of spectral images of charr. The quality of the reconstructed image is analyzed in two metrics: CIELab error $\Delta \mathrm{E}$ for human vision,

$$
\Delta E=\sqrt{\left(\mathrm{L}-\mathrm{L}_{\mathrm{t}}\right)^{2}+\left(\mathrm{a}-\mathrm{a}_{\mathrm{t}}\right)^{2}+\left(\mathrm{b}-\mathrm{b}_{\mathrm{t}}\right)^{2}},
$$

where

$\mathrm{L}, \mathrm{a}, \mathrm{b}=\mathrm{CIEL} a \mathrm{~b}$ values for measured spectra, and

$\mathrm{L}_{\mathrm{t}}, \mathrm{a}_{\mathrm{t}}, \mathrm{b}_{\mathrm{t}}=\mathrm{CIELab}$ values for measured spectra and root-mean-square error RMSE for the spectra

$$
R M S E=\sqrt{\frac{\sum_{i=1}^{n}(S(i)-\breve{S}(i))^{2}}{n}},
$$

where

$\mathrm{n}=$ number of wavelengths,

$S=$ original, measured spectra, and

$\breve{S}=$ spectra approximation from transform. 


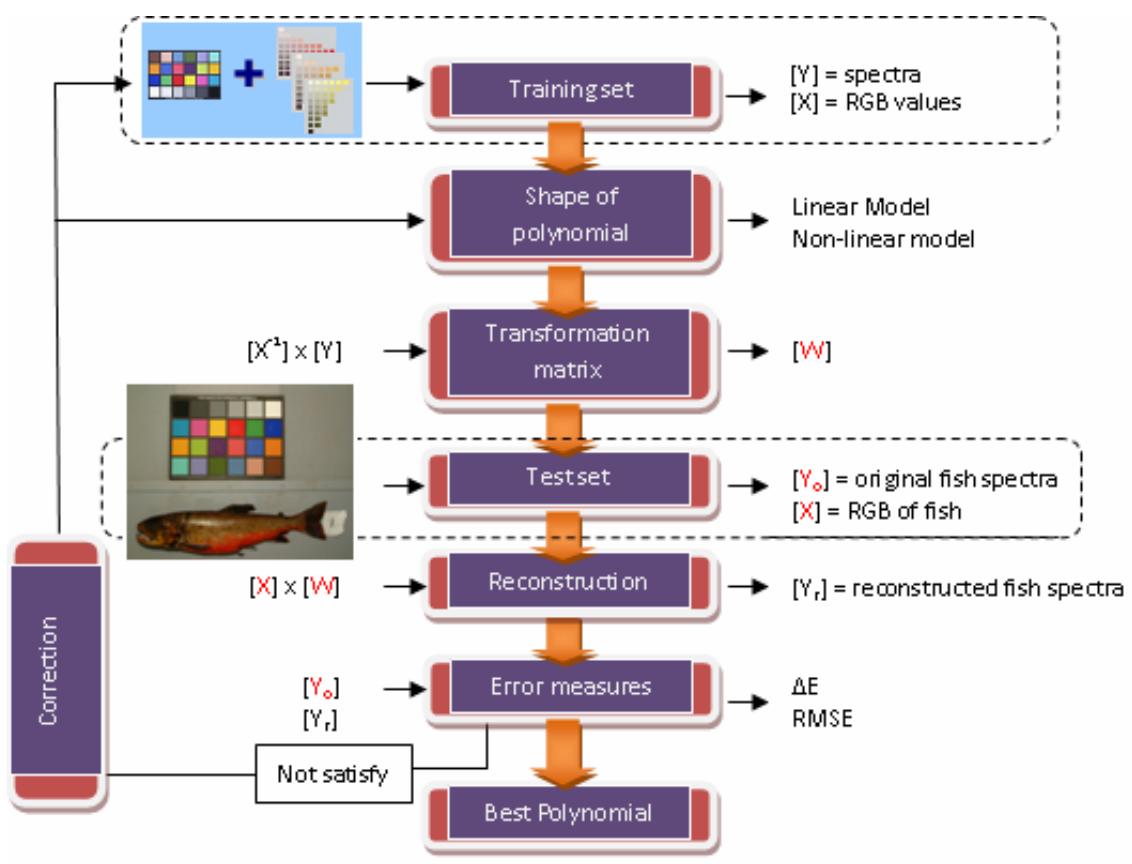

Fig. 1. Schema for spectral reconstruction

The best polynomial model is selected based on the error after the calculations. Table 1 shows terms of $2^{\text {nd }}$ and $3^{\text {rd }}$ polynomials which both have also a constant term $\left(1^{\text {st }}\right.$ order polynomial was excluded due its simplicity).

Table 1. Terms of polynomials

\begin{tabular}{ll}
\hline Number of terms & Terms of polynomials \\
\hline 10 & R G B R R $\mathrm{G}^{2} \mathrm{~B}^{2}$ RG RB GB 1 \\
20 & R G B R R G $\mathrm{B}^{2}$ RG RB GB \\
& RGB RGG RBB GRR GBB \\
& BRR BGG R $\mathrm{G}^{3} \mathrm{~B}^{3} 1$ \\
\hline
\end{tabular}

\section{Reconstruction Results}

Two different training sample set where used in reconstruction. All training and fish data was first subjected to spectral measurements. Then the corresponding sRGB presentation was calculated under illuminant 'D65' which is the ideal daylight $6500 \mathrm{~K}$ light.

\subsection{Reconstruction with Macbeth Chart}

The training set consisted of all 24 samples of Macbeth chart. The $2^{\text {nd }}$ and $3^{\text {rd }}$ order polynomials were applied to calculate the transform. Fig.2 shows an example of 


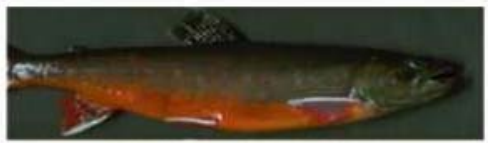

Original spectral image

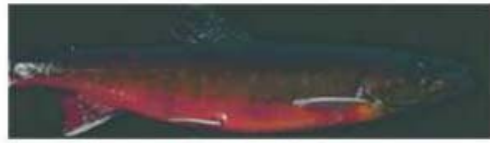

Reconstructed: 2nd order

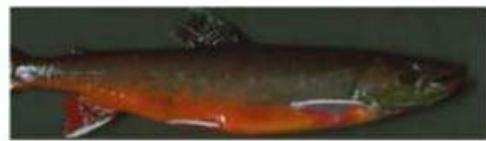

Reconstructed: 3rd order

Fig. 2. The upper image is a sRGB presentation calculated from the original spectral image. The lower row display sRGB presentations computed from polynomial approximated spectra: left image is obtained using 2nd order transform, while the right image is from 3rd order approximation.

results: sRGB presentation for original spectra and spectra approximated from sRGB. The $2^{\text {nd }}$ order approximation produces clearly color distortions for human point of view but color quality of $3^{\text {rd }}$ order approximation is acceptable.

The numerical evaluation of data is presented in Table 2 . The $3^{\text {rd }}$ order polynomial transform produces smaller $\Delta \mathrm{E}$ for the fish image than the $2^{\text {nd }}$ order one but RMSE is bigger for the $3^{\text {rd }}$ order. This indicates over fitting as shown in Fig. 3.

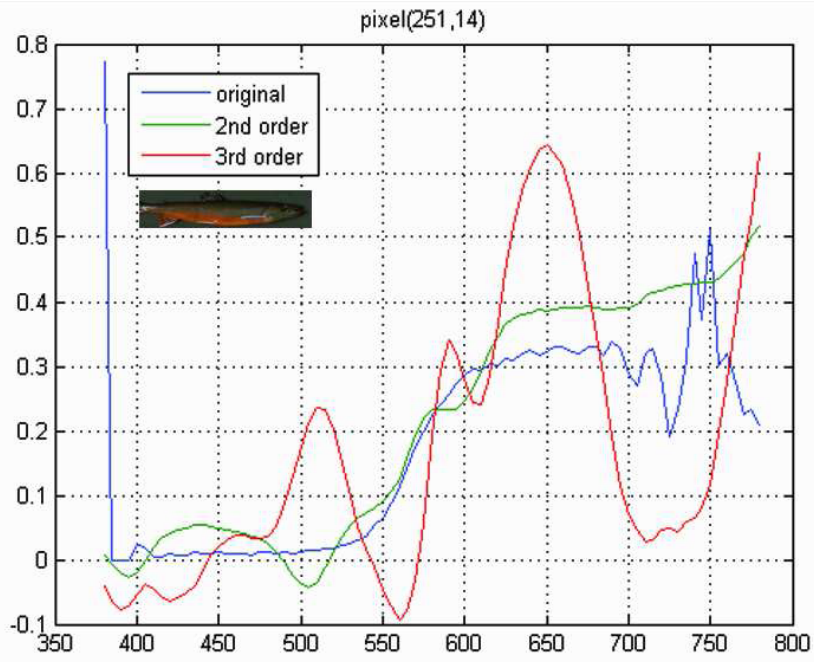

Fig. 3. The $3^{\text {rd }}$ order polynomial transform over fits the spectra. Note that the original spectral data is noisy at the ends of the wavelength range. 
Table 2. Numerical evaluation for Macbeth chart as a training set

\begin{tabular}{|c|c|c|c|c|c|}
\hline $\begin{array}{l}\text { Error } \\
\text { metric }\end{array}$ & & Average & $\begin{array}{l}\text { Standard } \\
\text { deviation }\end{array}$ & Maximum & Minimum \\
\hline \multirow[t]{6}{*}{$\Delta \mathrm{E}$} & \multicolumn{3}{|c|}{ Image of Fish } & & \\
\hline & $2^{\text {nd }}$ & 9.1862 & 6.9114 & 31.1366 & 0.1041 \\
\hline & $3^{\text {rd }}$ & 2.8097 & 2.8057 & 27.2516 & 0.003 \\
\hline & & Training & & & \\
\hline & $2^{\text {nd }}$ & 0.7511 & 0.5437 & 1.9430 & 0.1354 \\
\hline & $3^{\text {rd }}$ & 0.0551 & 0.0576 & 0.2244 & 0.0021 \\
\hline \multirow[t]{6}{*}{ RMSE } & & \multicolumn{2}{|c|}{ Image of Fish } & & \\
\hline & $2^{\text {nd }}$ & 1.6078 & 2.2106 & 11.3326 & 0.1819 \\
\hline & $3^{\text {rd }}$ & 3.186 & 3.5024 & 16.2798 & 0.2319 \\
\hline & & \multicolumn{2}{|c|}{ Training set } & & \\
\hline & $2^{\text {nd }}$ & 0.0354 & 0.0250 & 0.1229 & 0.0094 \\
\hline & $3^{\text {rd }}$ & 0.0262 & 0.0225 & 0.0916 & 0.0026 \\
\hline
\end{tabular}

\subsection{Reconstruction with Macbeth Chart and Pages from Munsell Book}

To solve the problem of over fitting, the training samples were complemented with few pages from Munsell book. Munsell book is a colour atlas which has a large number of samples for different hues. The sample pages selected from the book (like YY or RR) have hues similar to the hues present in Arctic charr. Fig. 4 displays the sRGB presentations for the new training data. The extended training set clearly improves color quality for $2^{\text {nd }}$ order model.

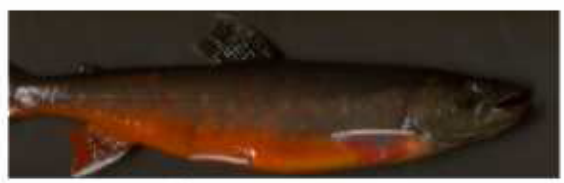

Original spectral image

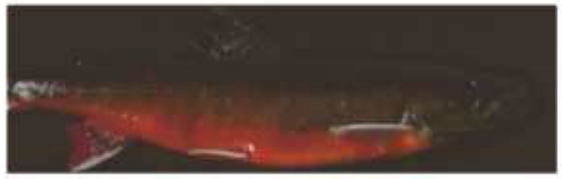

Reconstructed: 2nd order

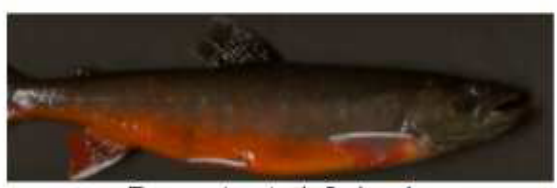

Reconstructed: 3rd order

Fig. 4. Upper row: sRGB from measured spectra. Lower row: left image, sRGB from $2^{\text {nd }}$ order transform and right image, sRGB from $3^{\text {rd }}$ order transform. The extended training set clearly reduces the color distortion in the $2^{\text {nd }}$ order polynomial transform. 
Table 3 and 4 presents the numerical errors $\triangle \mathrm{E}$ and RMSE obtained using different training set. The results indicate that the extending training set will reduce the average error in most of the cases, and that the 3rd order polynomial transform produces smaller errors. Tables 5 and 6 display the error calculated for skin patches of Arctic charr to test the transform with color variations. The results are the same also for these cases. The over fitting problem is also avoided as can be seen in Fig. 5.

Table 3. CIELab error

\begin{tabular}{llllll}
\hline $\begin{array}{l}\Delta \text { E error } \\
\text { Polynomial }\end{array}$ & Fish image & Average & $\begin{array}{c}\text { Standard } \\
\text { deviation }\end{array}$ & Maximum & Minimum \\
\hline $2^{\text {nd }}$ & Macb & 9.1862 & 6.9114 & 31.1366 & 0.1041 \\
& Mac+XYY & 7.7407 & 6.0777 & 28.2561 & 0.1058 \\
& Mac+XYY+XYR & 8.3574 & 6.4532 & 28.2481 & 0.0260 \\
$3^{\text {rd }}$ & Mac+YYRR(404) & 8.2703 & 7.1867 & 31.8375 & 0.0360 \\
& Macb & 2.8097 & 2.8057 & 27.2516 & 0.003 \\
& Mac+XYY & 3.0271 & 3.5854 & 26.9802 & 0.0147 \\
& Mac+XYY+XYR & 3.2334 & 3.1669 & 27.0605 & 0.0054 \\
$2^{\text {nd }}$ & Mac+YYRR(404) & 1.8174 & 2.9300 & 27.1408 & 0.0030 \\
& Training set & & & & \\
& Macb & 0.7511 & 0.5437 & 1.9430 & 0.1354 \\
& Mac+XYY & 1.3823 & 1.8873 & 17.8670 & 0.0617 \\
$3^{\text {rd }}$ & Mac+XYY+XYR & 1.0955 & 1.6314 & 18.0721 & 0.0821 \\
& Mac+YYRR(404) & 0.4700 & 0.5994 & 8.3434 & 0.0139 \\
& Macb & 0.0551 & 0.0576 & 0.2244 & 0.0021 \\
& Mac+XYY & 0.6849 & 1.3344 & 13.2440 & 0.0233 \\
& Mac+XYY+XYR & 0.5458 & 1.0999 & 13.9019 & 0.0116 \\
& Mac+YYRR(404) & 0.0571 & 0.1188 & 2.2247 & 0.0016 \\
\hline
\end{tabular}

Table 4. RMSE error for the extended training set

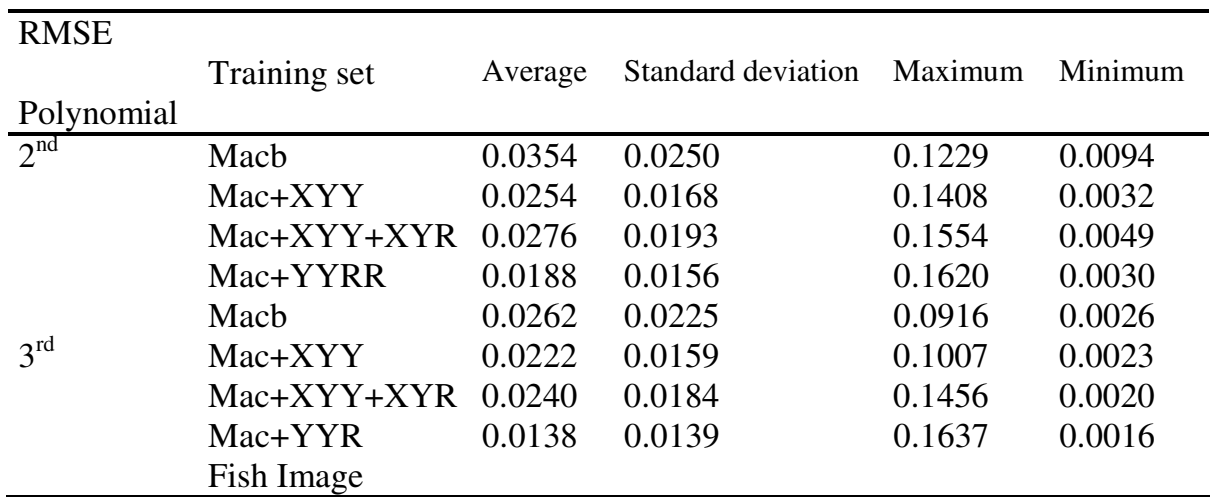


Table 4. (continued)

\begin{tabular}{|c|c|c|c|c|c|}
\hline \multirow[t]{4}{*}{$2^{\text {nd }}$} & Macb & 1.6078 & 2.2106 & 11.3326 & 0.1819 \\
\hline & $\mathrm{Mac}+\mathrm{XYY}$ & 1.5047 & 2.2076 & 11.0383 & 0.2475 \\
\hline & $\mathrm{Mac}+\mathrm{XYY}+\mathrm{XYR}$ & 1.4981 & 2.1945 & 11.0646 & 0.2938 \\
\hline & Mac+YYRR(404) & 1.4041 & 1.9767 & 9.8274 & 0.1737 \\
\hline \multirow[t]{4}{*}{$3^{\text {rd }}$} & Macb & 3.186 & 3.5024 & 16.2798 & 0.2319 \\
\hline & $\mathrm{Mac}+\mathrm{XYY}$ & 1.5418 & 2.3626 & 10.9252 & 0.1089 \\
\hline & $\mathrm{Mac}+\mathrm{XYY}+\mathrm{XYR}$ & 1.4258 & 2.3840 & 10.9380 & 0.1255 \\
\hline & Mac+YYRR(404) & 1.5349 & 2.1575 & 9.8115 & 0.0940 \\
\hline
\end{tabular}

Table 5. Numerical evaluation of a sample

\begin{tabular}{|c|c|c|c|c|c|}
\hline Polynomial & $\Delta \mathbf{E}$ & Average & $\begin{array}{l}\text { Standard } \\
\text { deviation }\end{array}$ & Maximum & Minimum \\
\hline \multirow[t]{2}{*}{$2^{\text {nd }}$} & Macb & 0.5867 & 0.3341 & 1.7043 & 0.0928 \\
\hline & Mac+YYRR & 0.2449 & 0.1011 & 0.9747 & 0.0149 \\
\hline \multirow[t]{2}{*}{$3^{\mathrm{rd}}$} & Macb & 0.2009 & 0.0978 & 0.3766 & 0.0014 \\
\hline & $\begin{array}{l}\text { Mac+YYRR } \\
\text { RMSE }\end{array}$ & 0.1534 & 0.0692 & 0.3573 & 0.0067 \\
\hline \multirow[t]{2}{*}{$2^{\text {nd }}$} & Macb & 0.3135 & 0.1812 & 0.7583 & 0.0636 \\
\hline & Mac+YYRR & 0.469 & 0.3878 & 1.1527 & 0.0584 \\
\hline \multirow[t]{2}{*}{$3^{\text {rd }}$} & Macb & 0.4224 & 0.5151 & 2.8739 & 0.063 \\
\hline & Mac+YYRR & 0.4886 & 0.417 & 1.2334 & 0.0584 \\
\hline
\end{tabular}

Table 6. Numerical evaluation of another sample

\begin{tabular}{llllll}
\hline & & & & \\
& & & & \\
& & & & \\
Polynomial & $\Delta \mathbf{E}$ & Average & $\begin{array}{l}\text { Standard } \\
\text { deviation }\end{array}$ & Maximum & Minimum \\
\hline $2^{\text {nd }}$ & Macb & 2.2833 & 2.2596 & 14.0901 & 0.0905 \\
& Mac+YYRR & 1.4028 & 1.2312 & 9.9955 & 0.42 \\
$3^{\text {rd }}$ & Macb & 0.3441 & 0.3428 & 4.1933 & 0.0023 \\
& Mac+YYRR & 0.445 & 0.2606 & 2.7709 & 0.0184 \\
$2^{\text {nd }}$ & RMSE & & & & \\
& Macb & 0.3835 & 0.3063 & 1.6232 & 0.0738 \\
$3^{\text {rd }}$ & Mac+YYRR & 0.2246 & 0.1044 & 0.5408 & 0.0629 \\
& Macb & 0.7983 & 0.6225 & 2.1389 & 0.0518 \\
& Mac+YYRR & 0.296 & 0.1587 & 0.6033 & 0.0528 \\
\hline
\end{tabular}



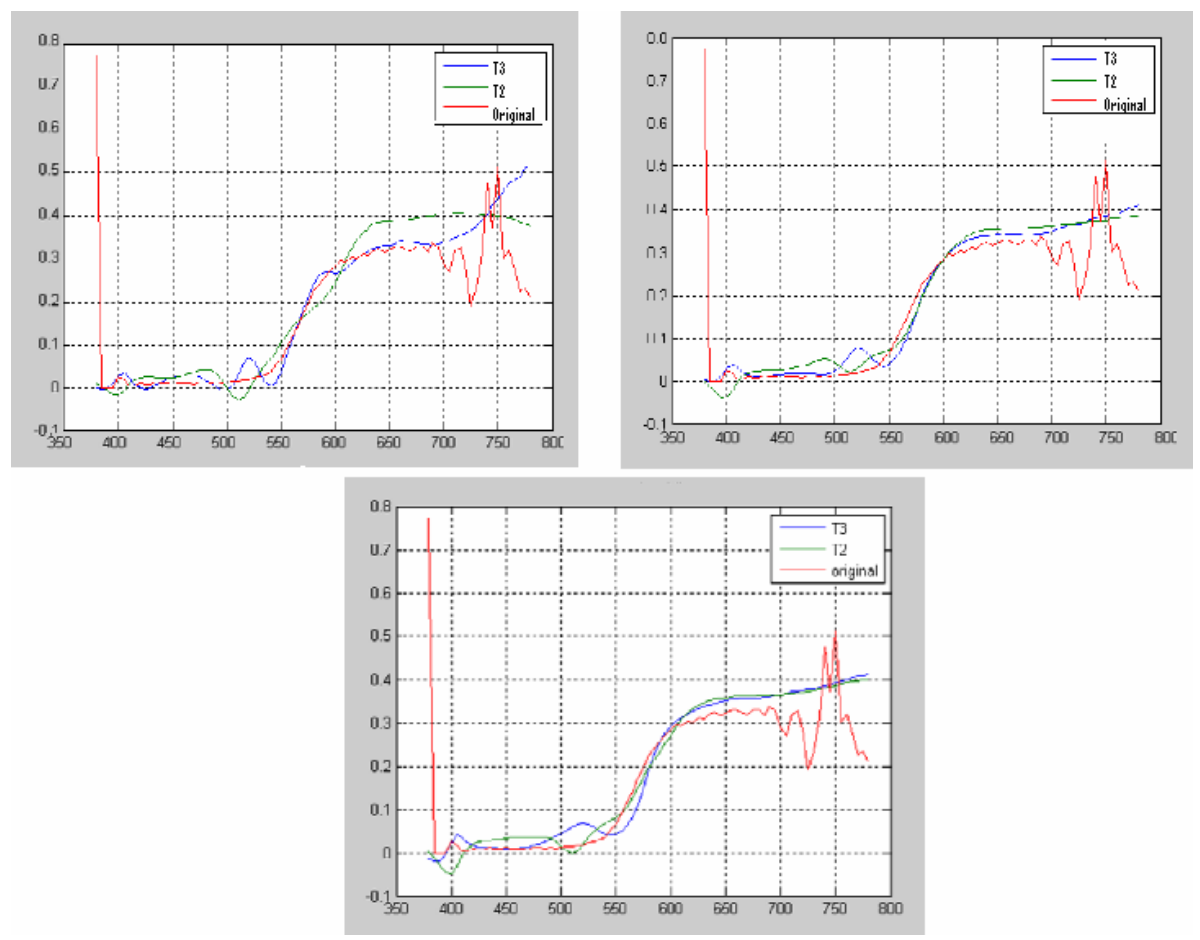

Fig. 5. The extended training set reduces the over fitting problem. Upper row, left image: training set Macbeth chart + Munsell YY; right image: Macbeth + Munsell YY and YR. The lower row, training set Macbeth chart + Munsell YY, YR and RR.

\section{Conclusions}

We have tested two polynomial regression models, $2^{\text {nd }}$ and $3^{\text {rd }}$ order polynomials, for sRGB-to-spectra transform with different training sets. The results indicate that a bare Macbeth chart will produce poor results both polynomials (color distortion and over fitting) when tested with Arctic charr. When adding more training samples from Munsell book corresponding to Arctic charr coloration, the models work better.

The obtained results clearly show that we can use RGB image to approximate the spectra for Arctic charr and thus make it as part of spectral based carotenoid content evaluation system.

\section{References}

1. Urho, L., Lehtonen, H.: Fish species in Finland. Riista- ja kalatalous - selvityksiä 18/2008 Finnish Game and Fisheries Research Institute, Helsinki (2008)

2. Badyaev, A.V., Hill, G.E.: Evolution of sexual dichromatism: contribution of carotenoidversus melanin-based coloration. Biological Journal of the Linnean Society 69, 153-172 (2000) 
3. Baronti, S., Casini, A., Lotti, F., Porcinai, S.: Multispectral imaging system for the mapping of pigments in works of art by use of principal-component analysis. Applied optics 37(8), 1299-1309 (1998)

4. Bochko, V., Tsumura, N., Miyake, Y.: A Spectral color imaging system for estimating spectral reflectance of paint. Journal of Imaging Science and Technology 51(1), 70-78 (2007)

5. Hardeberg, J.Y.: Acquisition and reproduction of colour images: colorimetric and multispectral approaches. Ph.D dissertation (Ecole Nationale Superieure des Telecommunications), Paris, France (1999)

6. Heikkinen, V., Jetsu, T., Parkkinen, J., Hauta-Kasari, M., Jaaskelainen, T., Lee, S.D.: Regularized learning framework in the estimation of reflectance spectra from camera responses. Journal of the Optical Society of America A 24(9), 2673-2683 (2007)

7. Shatilova, Y.: Color Image Technique in Fish Research, Master thesis, University of Joensuu (2008) 